\title{
Process Parameters Optimization for Maximizing Tensile Strength in Friction Stir-Welded Carbon Steel
}

\author{
Anmol Bhatia1,2,* - Reeta Wattal2 \\ ${ }^{1}$ The NorthCap University, Department of Mechanical Engineering, India \\ 2Delhi Technological University, Department of Mechanical Engineering, India
}

The present study focuses on improving the ultimate tensile strength of friction stir welded carbon steel (AISI 1018). The effect of the process parameters (welding speed, tool RPM, and shoulder diameter) on the response parameters (ultimate tensile strength, percentage elongation and percentage reduction in area) were studied. Response surface methodology was used to develop the mathematical model for response parameters, and the adequacy of the model was checked using analysis of variance (ANOVA). The welding speed and tool RPM were found to affect the ultimate tensile strength significantly. The percentage elongation was affected only by welding speed. The percentage reduction in the area was affected by welding speed and shoulder diameter. The microstructure and microhardness of the weld have been studied and reported in the study.

Keywords: friction stir welded steel, ANOVA, response surface methodology, ultimate tensile strength, microstructure and microhardness

\section{Highlights}

- In the present study, experimental analysis was done on friction stir-welded AISI1018 carbon steel joints to determine the effect of process parameters on response parameters (i.e., ultimate tensile strength, percentage elongation and percentage reduction in area) by developing mathematical models using the response surface methodology.

- $\quad$ The developed regression models proved to be adequate for determining the output response on friction stir-welded steel joints at a $95 \%$ confidence interval.

- $\quad$ The surface plots are also presented in the study, which illustrates the individual effect of process parameters on the mechanical properties of the friction stir-welded steel joint.

- The microstructure and microhardness of the friction stir-welded steel joint under optimized condition are also presented, and the observable pattern is presented in detail.

\section{INTRODUCTION}

Steel is the most popular choice of engineers because it has a good combination of mechanical properties and is the most widely used material for industrial applications. Steel is generally welded with a fusion-welding process that leads to various problems, including porosity, hot cracking, hydrogen embrittlement, microstructural changes in the heataffected zone, etc. [1]. The reason for the occurrence of these defects is mainly due to the inherent melting of base metal.

In order to overcome these defects, the friction stir-welding process is considered the best choice as it does not involve the melting of workpiece; thus, the chance of defects arising due to melting are eliminated. The process was patented by The Welding Institute, U.K. [2]. The setup consists of a non-consumable tool having a shoulder through which a small pin is extended. The plates that are to be welded are rigidly fixed, and the rotating tool is plunged within the joint of plates to the extent the shoulder touches the plate surface, resulting in the generation of heat. This localized heating results in softening the material around the pin. The material moves from the front to the back of the pin because of the rotational and translational movements of the tool; in this manner, a solid-state joint is produced [3].

The initial work on friction stir welding was done on aluminium and its alloys, as they have a low melting point [4] to [6]. Many aluminium alloys like Al $7075, \mathrm{Al} 6063$ [7] to [9] were the popular choice of the researchers. Then, the microstructural examinations were carried out on those alloys [10] and [11]. Later, the process parameter optimization studies were reported on friction stir-welded aluminium and its alloys [12] and [13]; other studies including corrosion analysis and tensile strength optimization were also reported for aluminium [14] to [16] and magnesium alloys [17] but nowadays the research focus is on high-temperature materials. A feasibility study related to friction stir welding of mild steel was initially presented by Linert et al. [18], in which defect-free welds were successfully produced, but excessive tool wear was reported; the paper emphasized the need to work on the geometry of the tool in order to eliminate the issue of tool wear. The study demonstrated that the friction stir-welding of mild steel is feasible 
without the loss of tensile properties. Ueji et al. [19] butt-welded ultra-fine plain low carbon steel with the help of a tungsten carbide tool. The paper reported the microstructural characterization and microhardness of the joint, but no mechanical testing was performed on the weld.

Thereafter, a study on friction stir-welded 1012 and 1035 carbon steels was conducted by Fujii et al. [20] using a tungsten carbide tool; the paper presented the effect of welding speed on the ultimate tensile strength of the weld nugget; mechanical properties and microstructural examination were also presented. An effort was then made to weld high carbon steel using FSW by Cui et al. [21]; the study was conducted on AISI 1070 material using a tungsten carbide tool. Metallurgical examinations were reported in the paper with an enhanced joint strength than the base metal. The effect on friction stir-welding conditions on the properties and microstructure was reported by Miles et al. [22]; the paper concluded that desired mechanical properties can be achieved by adjusting the process parameters. Later, a study was conducted by Ghosh et al. [23] in which the effect of process parameters was analysed on friction stir-welded medium carbon steel; the paper concluded that the strength of the stir zone was higher than the parent metal, and HAZ was reported to be the weakest section. Also, the ductility of the weld was found to be lower than the base metal. Lakshminarayanan et al. [24] conducted friction stir welding on $5 \mathrm{~mm}$ thick AISI 1018 plates using a tungsten carbide tool and reported an increased tensile strength value as compared to the base metal. The microstructural examination was also reported in the paper in which smaller pearlitic structures were observed in the weld region. Ghosh et al. [25] performed experimental analysis on lapwelded friction stir-welded M190 steel sheets. The variable parameters were kept as rotational and transverse speeds with the range of $600 \mathrm{~mm} / \mathrm{s}$ to 1200 $\mathrm{mm} / \mathrm{s}$ and $0.85 \mathrm{~mm} / \mathrm{s}$ to $3.39 \mathrm{~mm} / \mathrm{s}$, respectively. The microstructural examination revealed three regions: the nugget and two heat affected zones (HAZ-1 and HAZ-2) in which HAZ-1 was reported the weakest region constituting ferrite pearlite structures, while HAZ-2 contains martensite along with the increased value of hardness. The authors also reported that the best process parameter window to obtain joint efficiency of more than $60 \%$ was $1000 \mathrm{rpm}$ tool rotational speed and 1.69 to 3.39 transverse speed. Yabuuchi et al. [26] analysed the effect of rotational speed on the microstructure and tensile strength of friction stir-welded oxide dispersion-strengthened steel. The investigations were carried out on the speed ranging from $250 \mathrm{rpm}$ to $400 \mathrm{rpm}$. The study revealed that the hardness was reduced when welding was carried out at all the speed because of the occurrence of recrystallisation. The change in ultimate tensile strength was also reported similar to the change in hardness, meaning that the joint strength was also reduced by grain growth. Karami et al. [27] analysed the effect of the tool rotational speed and transverse speed on microstructure and tensile behaviour of friction stir welded mild steel. A tunnel defect was observed in the specimens with lower welding speed or higher rotational speeds as the amount of heat input was not sufficient to provide enough flowability. The microstructural study indicated that the stir zone or HAZ had an austenitic structure and, on cooling, transforms to ferritic and pearlitic structures. The study also revealed that all the specimens exhibit high yield strength and a lower value of uniform elongation because of the fine microstructure in stir zone and heat affected zone of the welded specimen. The microstructural and tensile behaviour of friction stir-welded trip steel were studied by Mironov et al. [28], who reported that the thermal effect of welding gave rise to thermal softening of the material in HAZ and that martensite formation occurred in the stir zone. A premature failure was also reported during the tensile test, because of the non-homogeneous strain distribution that occurred because of microstructural changes. Mahmoudiniya et al. [29] applied a friction stir-welding technique to weld DP700 steel at different rotational speeds $600 \mathrm{rpm}, 800 \mathrm{rpm}$, and $1000 \mathrm{rpm}$. The authors evaluated the microstructural and mechanical properties of the weld; they reported the occurrence of ferrite bands in the stir zone at 600 rpm, which lead to reduced strength. For the condition of $800 \mathrm{rpm}$ and $1000 \mathrm{rpm}$, joint failure occurred at softened HAZ. The maximum joint strength was reported for the rotational speed of $800 \mathrm{rpm}$. Lee et al. [30] studied the friction stir welded medium $\mathrm{Mn}$ steel using a tungsten carbide tool. The paper reported an increase in ultimate tensile strength and total elongation because of the increased strain hardening rate.

Although few studies were conducted to analyse the effect of process parameters on microstructure and mechanical properties for friction stirwelded steels, there is a gap in understanding the mechanical properties and concerned microstructural characterization of the friction stir-welded mild steel. Therefore, an attempt is made to establish empirical relationships to determine the effect of tensile strength, percentage elongation and percentage reduction in area for a friction stir-welded AISI 1018 
joint. Analysis of variance was also incorporated to check the adequacy of the developed model. Thus, the objective of the present study is to investigate the effects of process parameters on output response parameters such as tensile strength, percentage elongation and percentage reduction in area. RSM is also incorporated to optimize the process parameters for tensile strength.

\section{MATERIAL AND METHODS}

A butt-welded joint was produced on friction stirwelding machine, which is developed by R.V. Machine Tools, India. Table 1 shows the specifications of the machine. The material chosen for the experimental analysis was AISI 1018, with a thickness of $3 \mathrm{~mm}$. The steel plate was $200 \mathrm{~mm}$ in length, $40 \mathrm{~mm}$ in breadth, and $3 \mathrm{~mm}$ thick. The composition and mechanical properties of the material is illustrated in Tables $2 \mathrm{a}$ and $\mathrm{b}$. The friction stir-welding was done with a tungsten carbide tool with $7 \%$ cobalt. The sectional view of the friction stir-welded plate with the start and stop position of the tool is illustrated in Fig. 1. The composition of the tool used in the present study was made with EDAX analysis and is presented in Fig. 2a.

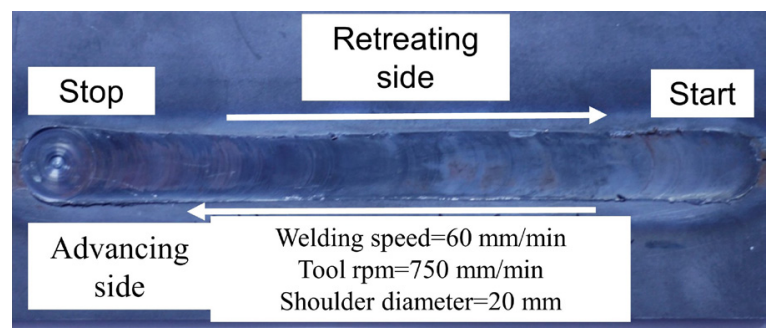

Fig. 1. Photograph of friction stir-welded joint

The dimensions of the tool used are presented in Fig. 2b. The profile of the tool pin used is presented in Fig. 2c. The length of the pin was kept as $2.6 \mathrm{~mm}$ so that its proper penetration takes place in the plates. A 1.5-degree tool tilt angle was kept throughout the experimentation, as shown in Fig. 2d. From the literature review, the process parameters chosen for the present study were welding speed, tool rpm, and shoulder diameter. These parameters are the major contributors in generating heat and affecting the tensile strength. The selected process parameters and their levels are tabulated in Table 3. The range of the selected parameters was determined by conducting several trials of input parameters in which obtaining the defect-free weld was the key factor. This was carried out by changing one of factors from minimum to maximum, keeping the other factors as constant.
The observations from the pilot experimentation are presented in Table 4.

Table 1. Specifications of friction stir welding machine used for experimentation

\begin{tabular}{lc}
\hline Spindle motor & $\begin{array}{c}11 \mathrm{~kW}, 1440 \mathrm{rpm}, 440 \mathrm{~V} \text { 3-Phase, AC } \\
\text { Drive, Flange mounting (STARK) }\end{array}$ \\
\hline Spindle speed & $1440 \mathrm{rpm}$ (max) \\
\hline Spindle housing tilting & Angle $\left(-5^{\circ}\right.$ to $\left.+5^{\circ}\right)$ \\
\hline Spindle pulley type & Timing Pulley \\
\hline Z-axis stroke & $300 \mathrm{~mm}$ \\
\hline Z-axis thrust & $\begin{array}{r}3922.6 \mathrm{~N} \text { (min)- } 39226.6 \mathrm{~N} \text { (max) } \\
\text { (Adjustable in steps) }\end{array}$ \\
\hline Z-axis feed rate & $0 \mathrm{~mm} / \mathrm{min}$ to $2000 \mathrm{~mm} / \mathrm{min}$ \\
\hline X-axis stroke & $600 \mathrm{~mm}$ \\
\hline Table & $600 \mathrm{~mm} \times 400 \mathrm{~mm}$ \\
& 'T' slot- $18 \mathrm{~mm} \times 3 \mathrm{~mm}$ \\
\hline Tool Holder & ISO 40 Taper-Side lock holder \\
\hline Z-axis feed force feedback & Load cells of capacity $5000 \mathrm{kgs}$, with \\
& least count $1 \mathrm{~kg}$ is provided \\
\hline Controller & PC based control system \\
\hline
\end{tabular}

Table 2a. Chemical composition of base metal (results by spectrometry)

\begin{tabular}{lccccc}
\hline Material & $\mathrm{C}[\mathrm{wt} \%]$ & $\mathrm{S}[\mathrm{wt} \%]$ & $\mathrm{Mn}[\mathrm{wt} \%]$ & $\mathrm{P}[\mathrm{wt} \%]$ & $\mathrm{Fe}[\mathrm{wt} \%]$ \\
\hline AISI 1018 Steel & 0.18 & 0.03 & 0.65 & 0.04 & Bal \\
\hline
\end{tabular}

Table 2b. Mechanical properties of base metal

\begin{tabular}{ccccc}
\hline $\begin{array}{c}\text { U.T.S. } \\
\text { [MPa] }\end{array}$ & $\begin{array}{c}\text { U.T.S. for reduced } \\
\text { section [MPa] }\end{array}$ & $\begin{array}{c}\text { Elongation } \\
{[\%]}\end{array}$ & $\begin{array}{c}\text { Yield strength } \\
\text { [MPa] }\end{array}$ & $\begin{array}{c}\text { Reduction } \\
\text { in area [\%] }\end{array}$ \\
\hline 416 & 435 & 21.8 & 280 & 50.77 \\
\hline
\end{tabular}

Table 3. Chosen process parameters with their levels

\begin{tabular}{lccccc}
\hline \multirow{2}{*}{ Parameter chosen } & \multirow{2}{*}{ Notation } & \multirow{2}{*}{ Units } & \multicolumn{3}{c}{ Levels } \\
\cline { 3 - 6 } & & & 1 & 2 & 3 \\
\hline Welding speed & $V$ & $\mathrm{~mm} / \mathrm{min}$ & 60 & 110 & 210 \\
\hline Tool rpm & $N$ & $\mathrm{~mm} / \mathrm{min}$ & 430 & 550 & 750 \\
\hline Shoulder diameter & $D$ & $\mathrm{~mm}$ & 15 & 18 & 20 \\
\hline
\end{tabular}

\section{EXPERIMENTATION}

The L9 orthogonal array was used as a design matrix for the conduction of experiments. Transverse tensile test specimens were prepared as per the E- 8 standard of ASTM [31]. Two tensile tests were conducted on the welds: transverse tensile testing and reduced section tensile testing. The former is used to locate the region of lowest strength in weldment and to determine the strength in that region; however, when the strength of weld nugget is to be determined then the later one that is reduced section tensile test is used in which area of the cross-section is deliberately reduced at 
a)

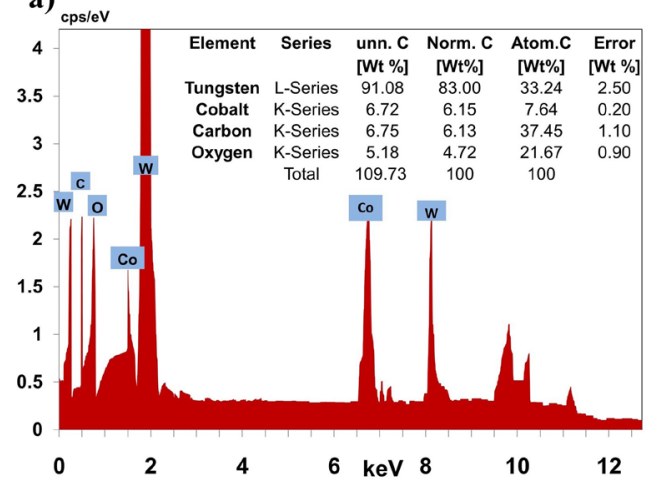

b)

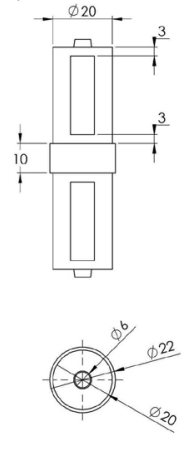

c)

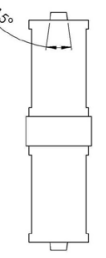

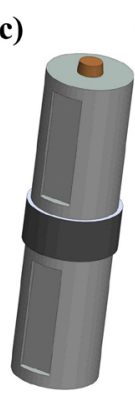

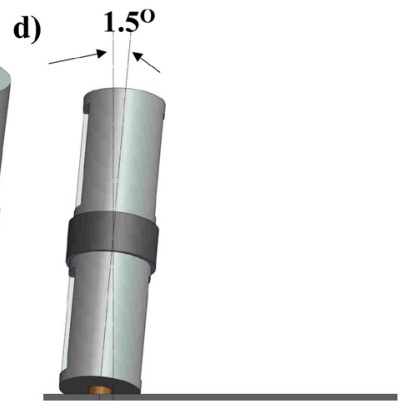

Fig. 2. a) Results obtained from EDAX analysis of tool, b) dimensions of the tool, c) tool profile, and d) 1.5-degree tool tilt angle used in generating the weld samples

Table 4. Observations made while selecting the range of process parameters

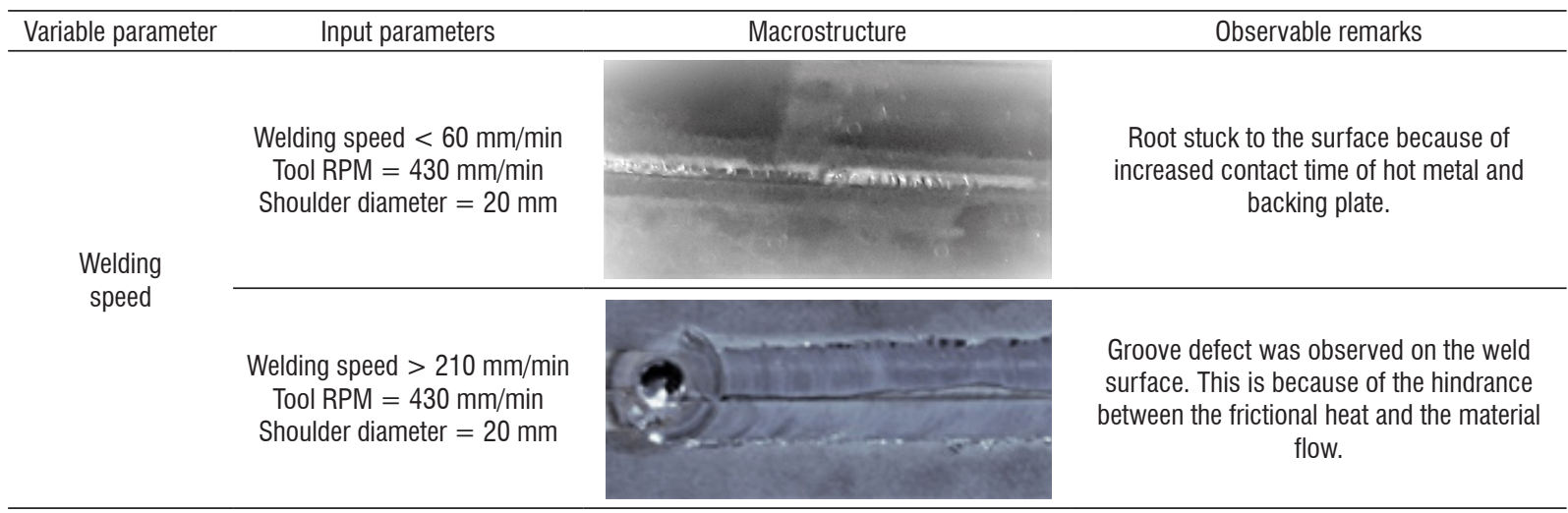

Tool RPM $<430 \mathrm{~mm} / \mathrm{min}$ Welding speed $=60 \mathrm{~mm} / \mathrm{min}$ Shoulder diameter $=20 \mathrm{~mm}$

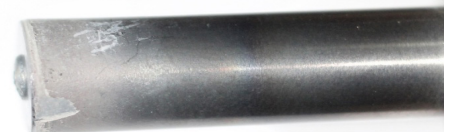

Excessive degradation of the tool pin was observed. This is due to the breakage of tool pin because of excessive heat generation.

Tool RPM

Tool RPM $>750 \mathrm{~mm} / \mathrm{min}$ Welding speed $=60 \mathrm{~mm} / \mathrm{min}$ Shoulder diameter $=20 \mathrm{~mm}$

Shoulder diameter $<15 \mathrm{~mm}$ Welding speed $=60 \mathrm{~mm} / \mathrm{min}$ Tool RPM $=430 \mathrm{~mm} / \mathrm{min}$

Shoulder diameter

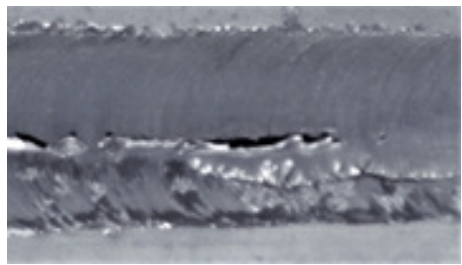

Tunnel defect with excessive flash was observed. The excessive flash occurred because of high rotational speed.
Shoulder diameter $>20 \mathrm{~mm}$ Welding speed $=60 \mathrm{~mm} / \mathrm{min}$ Tool RPM $=430 \mathrm{~mm} / \mathrm{min}$

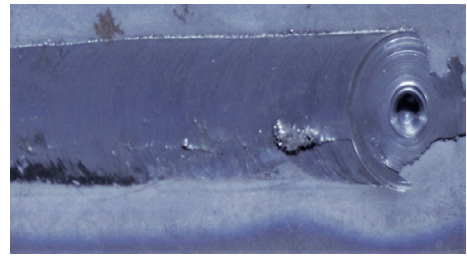

Surface defect was observed. This is because the area between the shoulder pin and shoulder diameter was reduced, which ultimately reduces the flow of material. 
weld nugget; this ensures that the transverse tensile test specimen fractures at the weld nugget region although weld nugget may not be the weakest region of the weldment. Three tensile test specimens were prepared for each welding condition. The samples for tensile test, microhardness, and microstructure evaluation were extracted from the welded specimen, as illustrated in Fig. 3a.

The dimensions of the transverse tensile test specimen and reduced section tensile test specimen are shown in Fig. 3b and Fig. 3c, respectively. The tensile testing of the specimen was done with a Zwick/Roell Z250 computer-controlled machine. The speed of testing was restricted between $1.5 \mathrm{~mm} /$ min to $15 \mathrm{~mm} / \mathrm{min}$ according to the E-8 standard of ASTM; the average of the results of ultimate percentage elongation and percentage reduction in area for three specimens are recorded and tabulated in Table 5. The microstructure of the FSW joint for the optimized condition was observed with a scanning electron microscope. The specimen extracted for microstructural evaluation was further polished and etched with a $3 \%$ Nital solution.

Microhardness testing was done as per ASTM E-92. Vickers's hardness at a 100-gram load was taken over the wide region of the welded specimen under optimized conditions. The fractured tensile tested specimen was also observed under a scanning electron microscope to observe the fractured surface morphology.

\section{RESULTS AND DISCUSSIONS}

\subsection{Developing Mathematical Model}

Tensile strength is a function of process parameters such as welding speed $(V)$, tool $\mathrm{rpm}(N)$ and shoulder diameter $(D)$. As the number of levels of the above process parameters was three, so up to secondorder terms have been considered in the regression equation. The second-order regression equation used to represent the effect is represented by Eq. (1).

$$
\begin{aligned}
\text { Effect }= & \text { Constant }+b_{1}(V)+b_{2}(V)^{2}+b_{3}(\mathrm{~N})^{2} \\
& +b_{4}(\mathrm{~N})^{2}+b_{5}(D)+b_{6}(D)^{2}
\end{aligned}
$$

where $b_{1}, b_{2}, b_{3}, b_{4}, b_{5}$ and $b_{6}$ are the regression coefficients. During the regression analysis, some of the coefficients may come out to be zero, meaning that those parameters do not affect the particular mechanical property. Standard t-test and regression
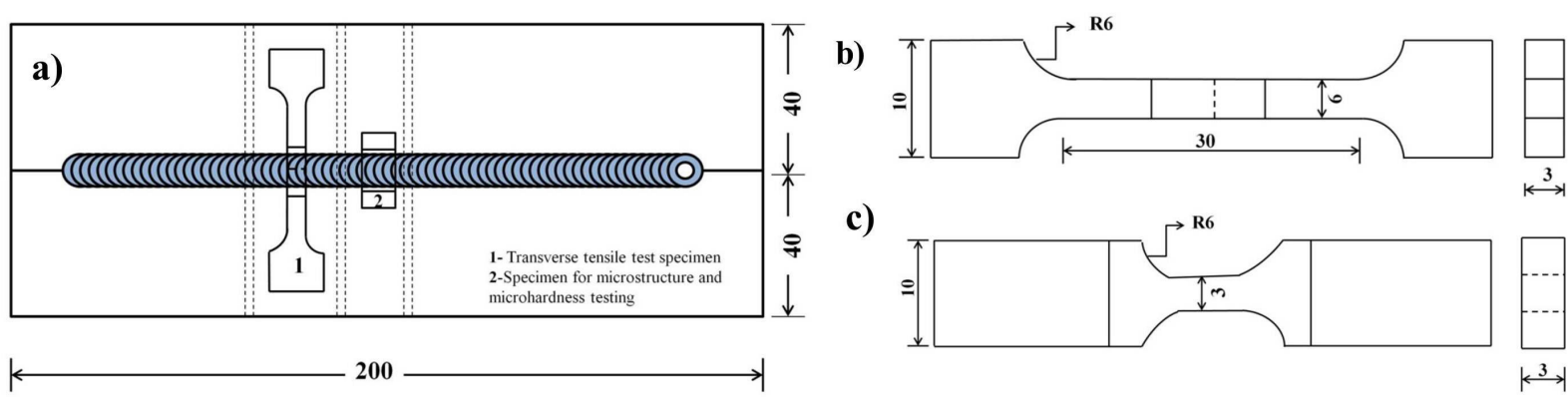

Fig. 3. a) Test coupon for taking out samples for mechanical and metallurgical testing, b) dimensions of transverse tensile test specimen, and c) dimensions of reduced section tensile test specimen

\begin{tabular}{|c|c|c|c|c|c|c|c|c|c|c|}
\hline \multirow{2}{*}{$\begin{array}{l}\text { Run } \\
\text { order }\end{array}$} & \multicolumn{3}{|c|}{ Coded values } & \multicolumn{3}{|c|}{ Original values } & \multirow{2}{*}{$\begin{array}{c}\text { For transverse tensile } \\
\text { test specimen }\end{array}$} & \multicolumn{3}{|c|}{ For reduced section specimen } \\
\hline & $V$ & $N$ & $D$ & $V$ & $N$ & $D$ & & UTS [MPa] & Elongation [\%] & Reduction in area [\%] \\
\hline 1 & 1 & 1 & 1 & 60 & 430 & 15 & 407.13 & 538.73 & 20.49 & 44.74 \\
\hline 2 & 1 & 2 & 2 & 60 & 550 & 18 & 430.00 & 460.70 & 20.62 & 45.72 \\
\hline 3 & 1 & 3 & 3 & 60 & 750 & 20 & 414.10 & 526.60 & 18.84 & 42.48 \\
\hline 4 & 2 & 1 & 2 & 110 & 430 & 18 & 408.83 & 533.56 & 22.00 & 58.82 \\
\hline 5 & 2 & 2 & 3 & 110 & 550 & 20 & 410.23 & 525.96 & 23.26 & 52.30 \\
\hline 6 & 2 & 3 & 1 & 110 & 750 & 15 & 408.53 & 549.76 & 23.82 & 47.93 \\
\hline 7 & 3 & 1 & 3 & 210 & 430 & 20 & 408.93 & 556.80 & 25.53 & 60.34 \\
\hline 8 & 3 & 2 & 1 & 210 & 550 & 15 & 410.60 & 525.16 & 24.29 & 64.55 \\
\hline 9 & 3 & 3 & 2 & 210 & 750 & 18 & 419.56 & 564.36 & 24.09 & 65.41 \\
\hline
\end{tabular}

Table 5. Run order and corresponding output responses 
analysis was performed using MINITAB software. $F$-test was also performed on the data at a $95 \%$ confidence level to prove that the data fit the proposed model.

The strength of the weld nugget could only be determined by using the reduced section tensile test specimen. The final mathematical model developed for reduced section specimen (i.e., ultimate tensile strength $[\mathrm{MPa}]$, elongation [\%] and reduction in area [\%]) is presented below:

$$
\begin{aligned}
& \text { UTS }=624.1+20.05(V)-162.2(N)+41\left(N^{2}\right), \\
& \text { Elongation }= 18.32+2.326(V), \\
& \text { Reduction in area }= 19.86+9.56(\mathrm{~V}) \\
&+18.02(D)-4.59\left(D^{2}\right) .
\end{aligned}
$$

Analysis of variance was done to identify the significant factors that affect the ultimate tensile strength, percentage elongation, and percentage reduction in area. The results of ANOVA are presented in Table 6.

\subsection{Checking the Adequacy of Developed Model}

To check the adequacy of the developed model, the coefficient of determination $\left(R_{E}^{2}\right)$ and the square root of the coefficient of determination $\left(R_{E}\right)$ were determined. The closer is the value of $R_{E}$ to one, the better is the model. The sum of the square of residual ( $S S$ residual), regression model sum of squares ( $S S$ model), mean square of residual ( $M S$ residual), and the degree of freedom $\left(D_{f}\right.$ model and $D_{f}$ residual) are used for the calculation of the coefficient of determination $\left(R_{E}^{2}\right)$. Adjusted $R_{E}^{2}$ that adjusts the number of terms in a model was also calculated. The correlation parameters for the developed model for the ultimate tensile strength, percentage elongation, and percentage reduction in area were calculated and are presented in Table 7. The ' $p$ ' value for all the developed models is less than 0.05 , which proves that the model is adequate.

Table 6a. ANOVA table for Ultimate tensile strength of reduced section specimen

\begin{tabular}{lcccc}
\hline Effect & Error & $t$-value & $p$-value & Significant \\
\hline Constant & 48.0293 & 12.5563 & 0.0000 & Yes \\
\hline Welding speed & 8.20525 & 3.7432 & 0.0406 & Yes \\
\hline (Welding speed) $^{2}$ & & Pooled & & \\
\hline Tool RPM & 53.5256 & -3.2989 & 0.0128 & Yes \\
\hline (Tool RPM) $^{2}$ & 13.2450 & 3.23889 & 0.0208 & Yes \\
\hline Shoulder diameter & & Pooled & No \\
\hline (Shoulder diameter) $^{2}$ & & Pooled & No \\
\hline
\end{tabular}

Table 6b. ANOVA table for percentage elongation of the weld

\begin{tabular}{lcccc}
\hline Effect & Error & $t$-value & $p$-value & Significant \\
\hline Constant & 0.8655 & 21.88 & 0.00000 & Yes \\
\hline Welding speed & 0.4021 & 5.334 & 0.00092 & Yes \\
\hline (Welding speed) $^{2}$ & & Pooled & & No \\
\hline Tool RPM & Pooled & No \\
\hline (Tool RPM) $^{2}$ & Pooled & No \\
\hline Shoulder diameter & Pooled & No \\
\hline (Shoulder diameter) $^{2}$ & Pooled & No \\
\hline
\end{tabular}

Table 6c. ANOVA table for percentage reduction in area of the weld

\begin{tabular}{lcccc}
\hline Effect & Error & $t$-value & $p$-value & Significant \\
\hline Constant & 6.993 & 2.5673 & 0.028756 & Yes \\
\hline Welding speed & 1.028 & 8.7654 & 0.000294 & Yes \\
\hline (Welding speed) $^{2}$ & \multicolumn{3}{c}{ Pooled } & No \\
\hline Tool RPM & Pooled & No \\
\hline (Tool RPM) $^{2}$ & \multicolumn{3}{c}{ Pooled } & No \\
\hline Shoulder diameter & 7.567 & 2.65431 & 0.041513 & Yes \\
\hline (Shoulder diameter) $^{2}$ & 1.889 & -2.65435 & 0.034563 & Yes \\
\hline
\end{tabular}

Table 7. Correlation parameters of the developed model

\begin{tabular}{lccc}
\hline $\begin{array}{l}\text { Correlation } \\
\text { parameter }\end{array}$ & For UTS & $\begin{array}{c}\text { For percentage } \\
\text { Elongation }\end{array}$ & $\begin{array}{c}\text { For percentage } \\
\text { reduction in area }\end{array}$ \\
\hline Multiple $R_{E}$ & 0.8938 & 0.97423 & 0.97231 \\
\hline Multiple $R_{E}{ }^{2}$ & 0.8038 & 0.8518 & 0.93831 \\
\hline Adjusted $R_{E}{ }^{2}$ & 0.6860 & 0.8024 & 0.90132 \\
\hline$S S$ model & 5801.13 & 32.7336 & 590.971 \\
\hline$D_{f}$ model & 1 & 1 & 3 \\
\hline$M S$ model & 1933.71 & 31.9065 & 196.990 \\
\hline$S S$ residual & 1530.286 & 7.1123 & 38.870 \\
\hline$D_{f}$ residual & 5 & 7 & 5 \\
\hline$M S$ residual & 308.6411 & 1.0349 & 7.7741 \\
\hline$F$ & 6.83 & 29.861 & 25.34 \\
\hline$P$ & 0.032 & 0.00094 & 0.002 \\
\hline
\end{tabular}

\subsection{Optimization of Welding Parameters}

In order to optimize the welding parameters, response surface methodology is used. Figs. 4 to 6 represent the surface plots and contour plots for UTS, percentage elongation, and percentage reduction in area for the different combination of process parameters.

\subsubsection{Effect of Process Parameters on UTS of Welds}

The temperature generated during welding is inversely proportional to welding speed. Thus, recrystallisation takes place at a lower temperature when welding is carried out at a higher speed, which restricts the grain growth after recrystallisation, which leads to a finer grain structure. Hence welding speed significantly 
affects the ultimate tensile strength, and the strength of the weld nugget increases with speed, but only at a maximum limit of welding speed. Hence, in order to achieve the maximum tensile strength, welding speed should be kept as high as possible.

The friction temperature also increases with the increase in tool RPM. This high temperature leads to softening of the material; therefore, the value of flow stress will become lower. Higher strain rates are also achieved by increasing tool RPM. When the tool RPM is increased initially, this factor is non-dominant as the increase in temperature largely governs the size of the recrystallized grain. On further increasing the tool RPM, the increase in the strain rate takes place, and the strength starts to increase, which can be seen clearly from Fig. 4.

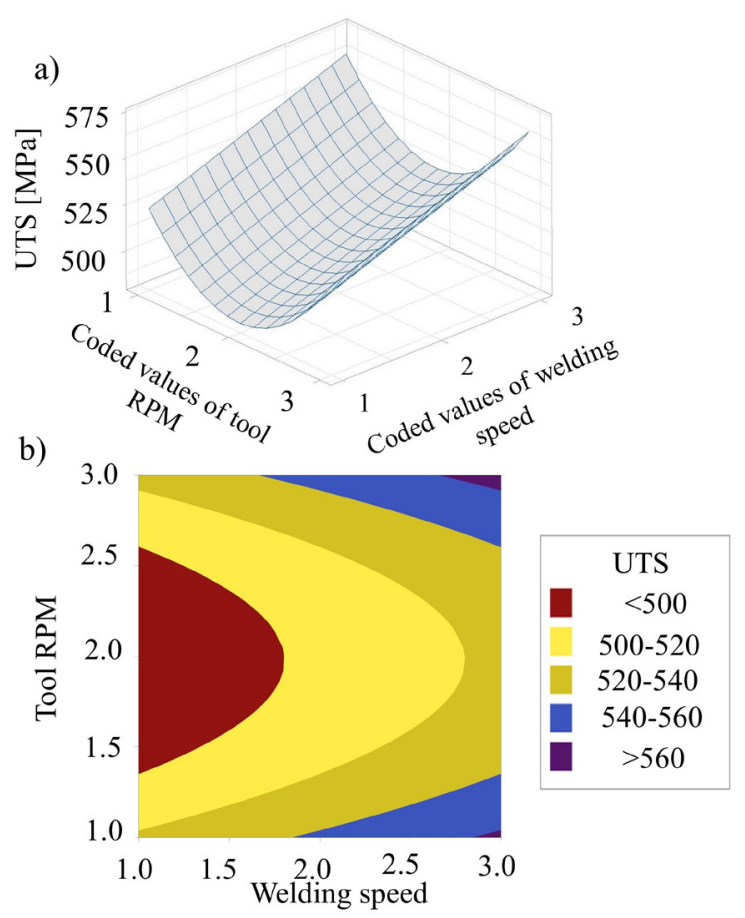

Fig. 4. a) Surface plot showing variation of UTS with the process parameters, and b) contour plot of UTS showing variations with process parameters

Increasing the tool shoulder diameter increases the amount of heat generated, but the larger tool diameter takes away the heat due to conduction. Therefore, due to the larger tool shoulder, the heat is spread over the larger area. Thus, this factor has not affected the ultimate tensile strength of the weld.

\subsubsection{Effect of Process Parameters on Percentage Elongation}

The percentage elongation depends upon the strain hardening behaviour of the material that is, in turn, dependent on the grain size. It is evident from Fig. 5 that the percentage elongation increases with the welding speed. This is because of the reduction in grain size due to the higher strain rates. The effect of Tool RPM in increasing the strain rate and increasing the temperature during welding seem to have compensated each other within the range; therefore, it is independent of variation of tool RPM. Also due to the larger tool diameter, heat is spread all over the larger area; thus, it does not affect the percentage elongation.
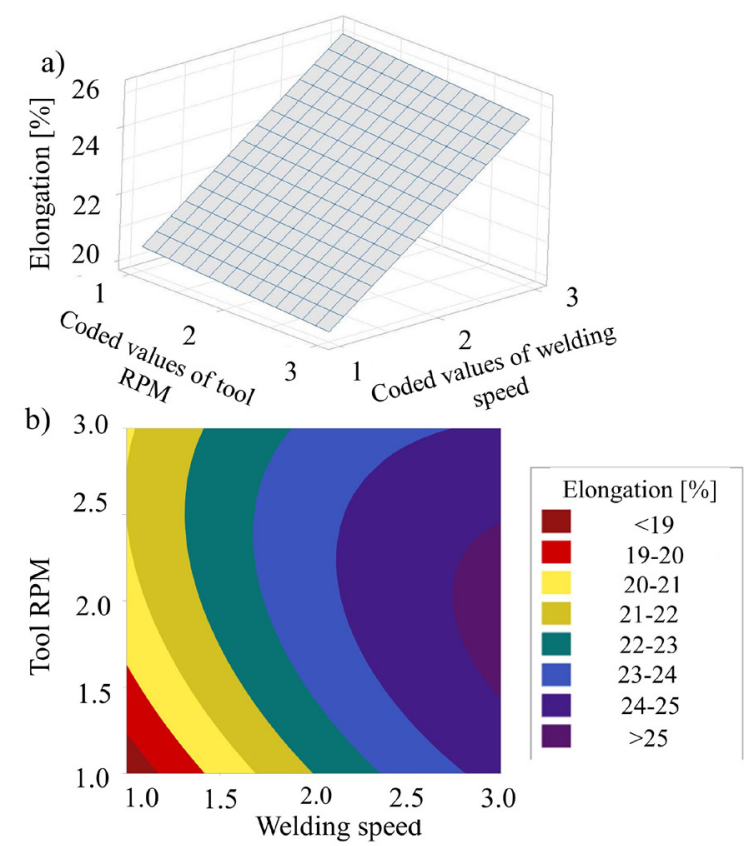

Fig. 5. a) Surface plot showing variation of percentage elongation with the process parameters, and b) contour plot of percentage elongation showing variations with process parameters

\subsubsection{Effect of Process Parameters on Percentage Reduction in Area}

As seen from Fig. 6, the percentage reduction in area increases with the welding speed. The reason for this is the reduction in grain size due to the higher strain rate. The effects of tool RPM in increasing the strain rate and increasing the temperature during welding seem to have compensated for each other within the range in which process parameters were varied. A 
slight effect of tool shoulder diameter is also observed on the percentage reduction in area.

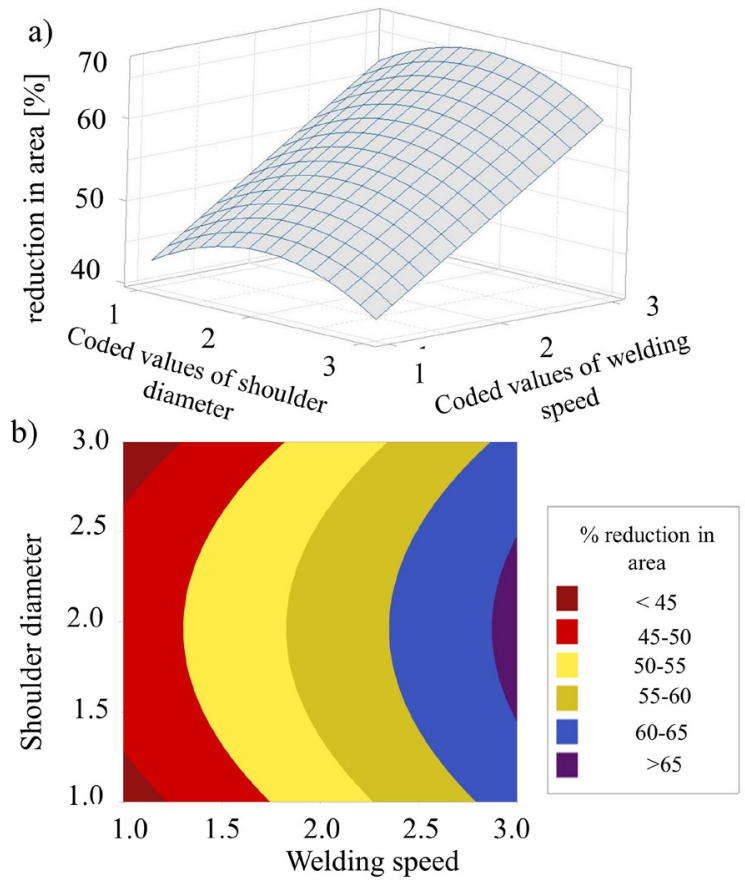

Fig. 6. a) Surface plot showing variation of percentage reduction in area with the process parameters, and b) contour plot of percentage reduction in area showing variations with process parameters

\subsection{Results of the Confirmation Experiment}

A predicted maximum tensile strength is $564.37 \mathrm{MPa}$ for the values of welding speed $210 \mathrm{~mm} / \mathrm{min}$, Tool $\mathrm{RPM}$ as $750 \mathrm{~mm} / \mathrm{min}$ and tool shoulder diameter as 20 $\mathrm{mm}$. The value of UTS as determined experimentally under the same conditions was 553.5 $\mathrm{MPa}$, which shows the consistency of the model. The results of the confirmation experiment are illustrated in Table 8.

\subsection{Observations on Microstructure}

Fig. 7 illustrates the microstructure of the weld obtained under optimized conditions at different locations. The location from which the micrographs have been taken is shown in Fig. 7. The base metal exhibits ferrites and small grains of pearlites, as shown in Fig 7a. The optical micrograph consists of regions containing the fine-grained heat-affected zone, interface between heat affected zone and stir zone, subregion inside the weld nugget as shown by Figs. $7 \mathrm{~b}$ to $\mathrm{d}$. The reason behind this ferrite and pearlite growth is due to relatively slow cooling rates. Fig. $7 d$ represents the formation of refined grain structure in the stir zone.

The microstructural analysis reveals that heat affected zone consists of ferrite and pearlites. The ferrites are represented by the light-etched constituents, and pearlite is represented by the darketched constituent. The refinement of grains was also observed in the stir zone as a result of which refined grain structures are observed in this zone. The boundary between the transformational zone is successfully identified, which shows the clear difference of recrystallisation.
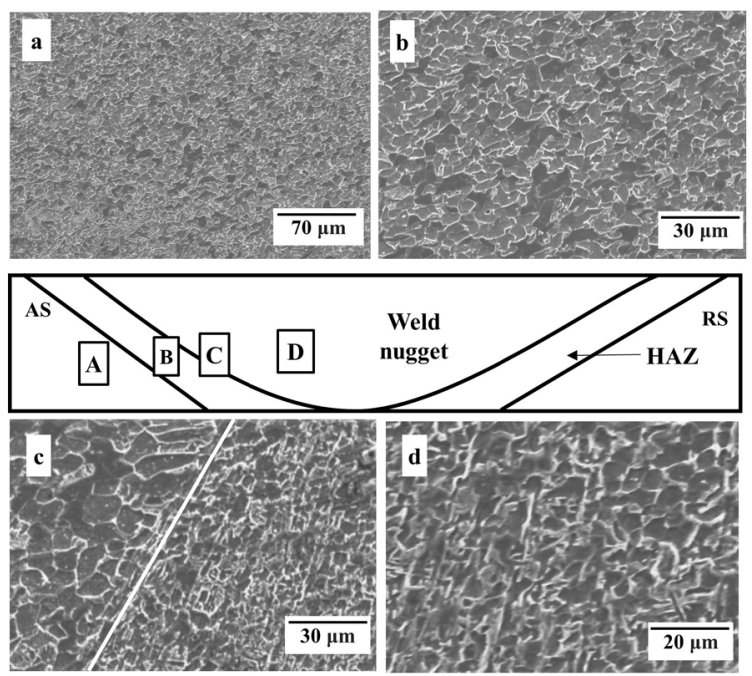

Fig. 7. Optical micrograph of various regions of the friction stir welded steel; a) base metal (region A), b) heat affected zone (region B), c) interface between the heat affected zone and stir zone (region $\mathrm{C}$ ), and d) stir zone (region $\mathrm{D}$ )

Table 8. Results of confirmation experiment

\begin{tabular}{cccccc}
\hline & Process parameters & \multicolumn{2}{c}{ Ultimate tensile strength } & Error \\
$\begin{array}{c}\text { Welding speed }(V) \\
{[\mathrm{mm} / \mathrm{min}]}\end{array}$ & $\begin{array}{c}\text { Tool RPM }(N) \\
{[\mathrm{mm} / \mathrm{min}]}\end{array}$ & $\begin{array}{c}\text { Shoulder diameter }(D) \\
{[\mathrm{mm}]}\end{array}$ & $\begin{array}{c}\text { Predicted value } \\
{[\mathrm{MPa}]}\end{array}$ & $\begin{array}{c}\text { Experimental value } \\
{[\mathrm{MPa}]}\end{array}$ & $\begin{array}{c}\text { [\% }] \\
210\end{array}$ \\
\hline 750 & 20 & 564.37 & 553.5 & 1.86 \\
\hline
\end{tabular}




\subsection{Observation on Microhardness of the Weld}

The plan followed for making indentations to conduct the microhardness testing is shown in Fig. 8. The specimen was polished on transverse section of the weld for testing purpose. Indentations were made $1 \mathrm{~mm}$ apart, covering the entire region of weldment on the transverse section. A total of $20 \mathrm{~mm}$ distance was covered during the indentation scheme, which was sufficient to cover the weld nugget, HAZ and a portion of the unaffected base material.

The results of the microhardness are shown in Fig. 9. The hardness taken in the stir zone shows a constituently high value. The microhardness values in the weld nugget are higher as compared to the base metal. Although the hardness values vary across the weld nugget, they never fall below the hardness value of base metal. The increase in hardness is primarily due to the fine grain structure of the weld nugget.

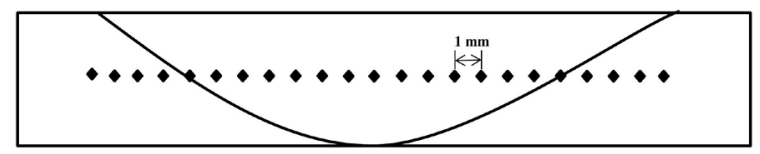

Fig. 8. Scheme followed for making indentations for conducting microhardness test

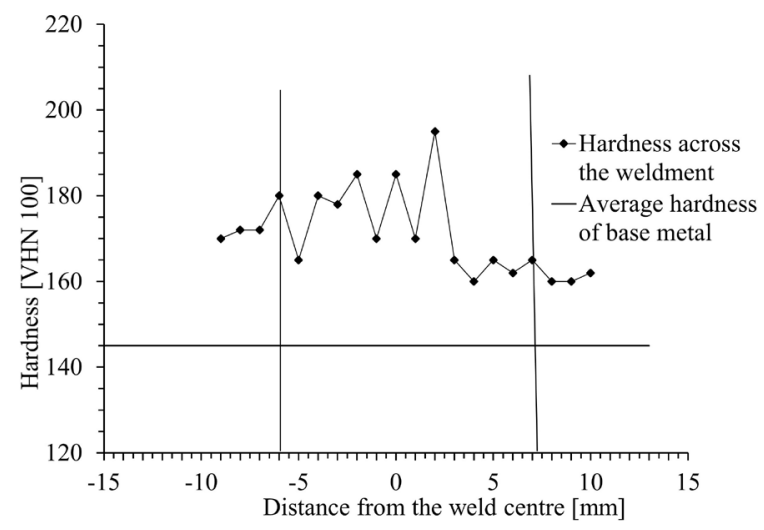

Fig. 9. Microhardness profile (transverse section) of the specimen welded under optimized conditions

\subsection{Fractured Surface}

Fig. 10 illustrates the microstructure of fractured tensile test specimen in which dimpled surfaces are predominantly seen over the entire area. The mode of failure appears to be ductile fracture, which is further confirmed by appearance of sheared surfaces and deformed craters.

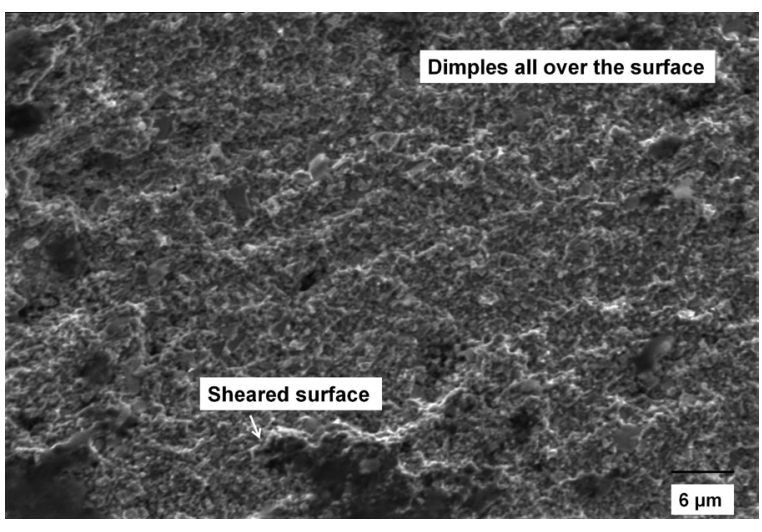

Fig. 10. SEM image of fractured joint region

\section{CONCLUSIONS}

The major conclusions that can be drawn from the present study are:

1. Mathematical models were developed for the ultimate tensile strength, percentage elongation and percentage reduction in area, using regression analysis and ANOVA was used to predict the tensile strength of the joint at a $95 \%$ confidence interval.

2. The weld nugget was reported to be the strongest region, and the unaffected base metal was reported to be the weakest region.

3. The confirmation experiment for ultimate tensile strength depicts that the developed model was adequate.

4. The ultimate tensile strength was significantly affected by the welding speed and tool RPM. The percentage elongation of the weld was affected by welding speed only, and the percentage reduction in the area was significantly affected by welding speed and tool shoulder diameter.

5. The microstructure of the welded joint for the optimized conditions was observed. Pearlite and ferrites were observed in the heat-affected zone, and refined pearlitic structures were observed in the stir zone.

6. The microhardness values in the weld nugget are higher as compared to the base metal. The increase in hardness is primarily due to the fine grain structure of the weld nugget.

7. The fracture morphology of the tensile test specimen was also carried out and revealed ductile fracture because the dimpled regions were observed over the entire area. 


\section{ACKNOWLEDGEMENTS}

The authors would like to thank DTU, Delhi for providing the Experimental setup and Central Research Facility, NCU, Gurugram for providing the necessary testing facilities required for the present study.

\section{REFERENCES}

[1] AWS. (1996). AWS Handbook, 8 $8^{\text {th }}$ ed., vol.3, American Welding Society, Miami.

[2] Thomas, W.M., Nicholas, E.D., Needham, J.C., Murch, M.G., Temple-Smith, P., Dawes, C.J. (1995). Friction Welding, Patent no. 5460317. United States Patent and Trademark Office (USPTO), Washington.

[3] Mishra, R.S., Ma, Z.Y. (2005). Friction stir welding and processing. Materials Science and Engineering: R: Reports, vol. 50, no. 1-2, p. 1-78, D0l:10.1016/j.mser.2005.07.001.

[4] Hassan, Kh.A.A., Norman, A.F., Price, D.A., Prangnell, P.B. (2003). Stability of nugget zone grain structures in high strength Al-alloy friction stir welds during solution treatment. Acta Materialia, vol. 51, no. 7, p. 1923-1936, Dol:10.1016/ s1359-6454(02)00598-0.

[5] Heinz, B., Skrotzki, B. (2002). Characterization of a frictionstir-welded aluminum alloy 6013. Metallurgical and Materials Transactions B, vol. 33, p. 489-498, D0l:10.1007/s11663002-0059-5.

[6] Liu, H.J., Fujii, H., Maeda, M., Nogi, K. (2003). Tensile properties and fracture locations of friction-stir-welded joints of 2017-T351 aluminum alloy. Journal of Materials Processing Technology, vol. 142, no. 3, p. 692-696, Dol:10.1016/s09240136(03)00806-9.

[7] Mahoney, M.W., Rhodes, C.G., Flintoff, J.G., Bingel, W.H., Spurling, R.A. (1998). Properties of friction-stir-welded 7075 T651 aluminum. Metallurgical And Materials Transactions A, vol. 29, p. 1955-1964, Dol:10.1007/s11661-998-0021-5.

[8] Sato, Y.S., Kokawa, H. (2001). Distribution of tensile property and microstructure in friction stir weld of 6063 aluminum. Metallurgical and Materials Transactions A, vol. 32, p. 30233031, DOI:10.1007/s11661-001-0177-8.

[9] Sato, Y.S., Kokawa, H., Enomoto, M., Jogan, S., Hashimoto, T. (1999). Precipitation sequence in friction stir weld of 6063 aluminum during aging. Metallurgical and Materials Transactions A, vol. 30, p. 3125-3130, D0l:10.1007/s11661999-0223-5.

[10] Sato, Y.S., Urata, M., Kokawa, H., Ikeda, K. (2003). Hall-petch relationship in friction stir welds of equal channel angularpressed aluminium alloys. Materials Science and Engineering: A, vol. 354, no. 1-2, p. 298-305, D0l:10.1016/s09215093(03)00008-x.

[11] Su, J.-Q., Nelson, T.W., Mishra, R., Mahoney, M. (2003). Microstructural investigation of friction stir welded 7050T651 aluminium. Acta Materialia, vol. 51, no. 3, p. 713-729, DOI:10.1016/s1359-6454(02)00449-4.

[12] Lakshminarayanan, A.K., Balasubramanian, V. (2008). Process parameters optimization for friction stir welding of
RDE-40 aluminium alloy using Taguchi technique. Transactions of Nonferrous Metals Society of China, vol. 18, no. 3, p. 548554, DOI:10.1016/s1003-6326(08)60096-5.

[13] Vijayan, S., Raju, R., Rao, S.R.K. (2010). Multiobjective optimization of friction stir welding process parameters on aluminum alloy AA 5083 using Taguchi-based grey relation analysis. Materials and Manufacturing Processes, vol. 25, no. 11, p. 1206-1212, DOl:10.1080/10426910903536782.

[14] Elatharasan, G., Senthil Kumar, V.S. (2014). Corrosion analysis of friction stir-welded AA 7075 aluminium alloy. Strojniški vestnik - Journal of Mechanical Engineering, vol. 60, no. 1, p. 29-34, DOI:10.5545/sv-jme.2012.711.

[15] Kadaganchi, R., Gankidi, M.R., Gokhale, H. (2015). Optimization of process parameters of aluminum alloy AA 2014-T6 friction stir welds by response surface methodology. Defence Technology, vol. 11, no. 3, p. 209-219, Dol:10.1016/j. dt.2015.03.003.

[16] Babu, N., Karunakaran, N., Balasubramanian, V. (2017). A study to estimate the tensile strength of friction stir welded AA 5059 aluminium alloy joints. The International Journal of Advanced Manufacturing Technology, vol. 93, p. 1-9, DOl:10.1007/s00170-015-7391-9.

[17] Satheesh, C., Sevvel, P., Senthil Kumar, R. (2020). Experimental identification of optimized process parameters for FSW of Az91C mg alloy using quadratic regression models. Strojniški vestnik - Journal of Mechanical Engineering, vol. 66, no. 12, p. 736-751, Dol:10.5545/sv-jme.2020.6929.

[18] Lienert, T.J., Stellwag, W.L., Jr., Grimmett, B.B., Warke, R.W. (2003). Friction stir welding studies on mild steel. Supplement To The Welding Journal, vol. 82, p. 1s-9s.

[19] Ueji, R., Fujii, H., Cui, L., Nishioka, A., Kunishige, K., Nogi, K. (2006). Friction stir welding of ultrafine grained plain lowcarbon steel formed by the martensite process. Materials Science and Engineering: A, vol. 423, no. 1-2, p. 324-330, DOI:10.1016/j.msea.2006.02.038.

[20] Fujii, H., Cui, L., Tsuji, N., Maeda, M., Nakata, K., Nogi, K. (2006). Friction stir welding of carbon steels. Materials Science and Engineering: A, vol. 429, no. 1-2, p. 50-57, D0l:10.1016/J.msea.2006.04.118.

[21] Cui, L., Fujii, H., Tsuji, N., Nogi, K. (2007). Friction stir welding of a high carbon steel. Scripta Materialia, vol. 56, no. 7, p. 637-640, DOI:10.1016/j.scriptamat.2006.12.004.

[22] Miles, M.P., Nelson, T.W., Steel, R., Olsen, E., Gallagher, M. (2009). Effect of friction stir welding conditions on properties and microstructures of high strength automotive steel. Science and Technology of Welding and Joining, vol. 14, no. 3, p. 228-232, DOl:10.1179/136217108x388633.

[23] Ghosh, M., Hussain, M., Kumar Gupta, R. (2012). Effect of welding parameters on microstructure and mechanical properties of friction stir welded plain carbon steel. ISIJ International, vol. 52, no. 3, p. 477-482, Dol:10.2355/ isijinternational.52.477.

[24] Lakshminarayanan, A.K., Balasubramanian, V., Salahuddin, M. (2010). Microstructure, tensile and impact toughness properties of friction stir welded mild steel. Journal of Iron and Steel Research International, vol. 17, p. 68-74, D0I:10.1016/ s1006-706x(10)60186-0. 
[25] Ghosh, M., Kumar, K., Mishra, R.S. (2012). Process optimization for friction-stir-welded martensitic steel. Metallurgical and Materials Transactions A, vol. 43, p. 19661975, DOI:10.1007/s11661-012-1084-x.

[26] Yabuuchi, K., Tsuda, N., Kimura, A., Morisada, Y., Fujii, H., Serizawa, H., Nogami, S., Hasegawa, A., Nagasaka, T. (2014). Effects of tool rotation speed on the mechanical properties and microstructure of friction stir welded ODS steel. Materials Science and Engineering: A, vol. 595, p. 291-296, DOI:10.1016/j.msea.2013.12.022.

[27] Karami, S., Jafarian, H., Eivani, A.R., Kheirandish, S. (2016). Engineering tensile properties by controlling welding parameters and microstructure in a mild steel processed by friction stir welding. Materials Science and Engineering: $A$, vol. 670, p. 68-74, Dol:10.1016/j.msea.2016.06.008.

[28] Mironov, S., Sato, Y.S., Yoneyama, S., Kokawa, H., Fujii, H.T., Hirano, S. (2018). Microstructure and tensile behavior of friction-stir welded trip steel. Materials Science and Engineering: A, vol. 717, p. 26-33, D0l:10.1016/j. msea.2018.01.053.

[29] Mahmoudiniya, M., Kokabi, A.H., Kheirandish, S., Kestens, L.A.I. (2018). Microstructure and mechanical properties of friction stir welded ferrite-martensite DP700 steel. Materials Science and Engineering: A, vol. 737, p. 213-222, DOI:10.1016/j.msea.2018.09.013.

[30] Lee, S.-J., Park, T.M., Nam, J.-H., Choi, W.S., Sun, Y., Fujii, H., Han, J. (2019). The unexpected stress-strain response of medium $\mathrm{Mn}$ steel after friction stir welding. Materials Science and Engineering: A, vol. 744, p. 340-348, D0l:10.1016/j. msea.2018.12.041.

[31] Standard test methods for tension testing of metallic materials, in E 8M-04,2004, ASTM International: West Conshohocken, PA 19428-2959, p. 1-6. 